\title{
DNA Sequencing of the eta Gene Coding for Staphylococcal Exfoliative Toxin Serotype A
}

\author{
By SUSUMU SAKURAI, ${ }^{1}$ HITOSHI SUZUKI ${ }^{1}$ AND ISAMU KONDO ${ }^{2}$ * \\ ${ }^{1}$ Division of Molecular Genetics, The Jikei University School of Medicine, Japan \\ ${ }^{2}$ Research Center, Taisho Pharmaceutical Co. Ltd, I-403, Yoshino-cho, Ohmiya-shi, 330 Japan
}

(Received 16 June 1987; revised 3 November 1987)

\begin{abstract}
We report the nucleotide sequence of a $1.45 \mathrm{~kb}$ segment containing the eta gene, coding for staphylococcal exfoliative toxin A (ETA), isolated from the recombinant plasmid pETA-J3. The coding region of $840 \mathrm{bp}$ specified a polypeptide of 280 amino acid residues which included a putative 38 residue signal sequence. The amino acid composition deduced from the structural gene was in agreement with the results of peptide analysis of the ETA molecule reported by others. The sequence of the $35 \mathrm{~N}$-terminal amino acid residues of ETA derived from Staphylococcus aureus strain ZM was also consistent with that deduced from the DNA sequencing.
\end{abstract}

\section{INTRODUCTION}

Infection of human neonates with certain Staphylococcus aureus strains can cause Ritter's disease, also known as the staphylococal scalded skin syndrome (SSSS). Since Melish \& Glasgow (1970) established a mouse model for bioassay of SSSS, rapid progress has been made in molecular studies of the disease, and it is now well established that the exfoliative toxin (ET) is the causative agent of SSSS (Melish \& Glasgow, 1970; Kapral \& Miller, 1971; Arbuthnott et al. 1971; Kondo et al., 1973, 1974, 1975). The most conclusive evidence for this is that administration of highly purified ET to mice reproduces the typical Nikolsky sign (NK), exfoliation of the epidermis seen in patients with Ritter's disease. Some inbred mice are able to produce antibodies to ET while others are non-producers. However, all mouse strains so far tested are susceptible to this toxin (Kondo \& Sakurai, 1980). Therefore, the mechanism of ET pathogenesis is independent of the immune response of the hosts. When rabbits were immunized with ET, a new toxin serotype (ETB), non-crossreactive to the existing ET (ETA), was discovered (Kondo et al., 1973). Structural differences between serotypes ETA and ETB are further suggested by differences in heat stability (Kondo et al., 1973, 1974). Also ETA is a metallo-toxin, containing one copper ion per molecule, whereas no metal is detectable in the ETB molecule (Kondo \& Sakurai, 1980). ETA is heterogeneous in isoelectric point while ETB is homogeneous (Kondo et al., 1974). In addition, ETA is coded by a chromosomal gene while ETB is plasmid-specified (Rogolsky et al., 1974, 1976; Wiley \& Rogolsky, 1977; Jackson \& Iandolo, 1986; O’Toole \& Foster, 1986a, $b$ ).

Although ETA and ETB are antigenically distinct, they presumably share some structures important for toxinogenesis. Therefore, we cloned the gene coding for ETA, eta, into pUC9 and transformed Escherichia coli $\mathrm{C} 600$ with the recombinant plasmid pETA, in order to analyse the properties of ETA. ETA produced by the E. coli transformant, cETA, was indistinguishable from the ETA produced by Staphylococcus aureus, sETA, in its physicochemical and serological properties and its ability to cause exfoliation. cETA did not remain in the periplasmic space of the $E$. coli transformants, and more than $97 \%$ of the toxin became extracellular (Sakurai et al., 1987).

Abbreviations: ETA, ETB, exfoliative toxin A, B; ORF, open reading frame. 


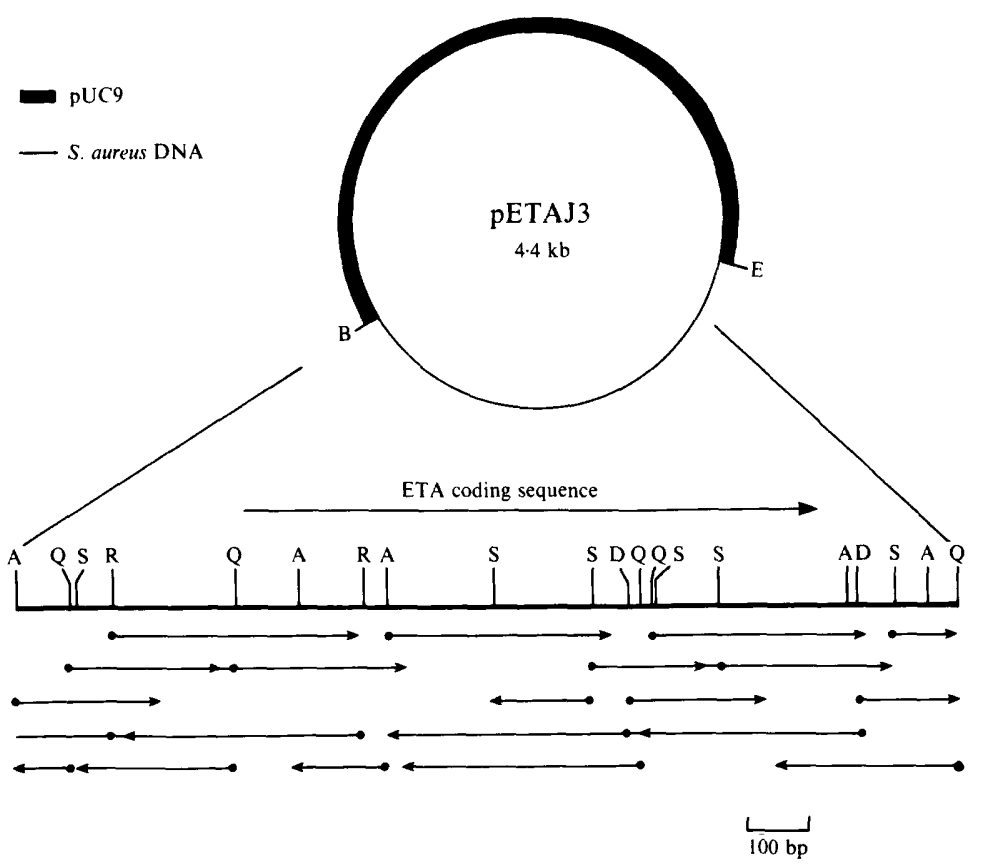

Fig. 1. Restriction map and sequencing strategy of the AluI-TaqI fragment of pETA-J3. Abbreviations of restriction endonucleases are as follows: A, AluI ; B, BamHI; E, EcoRI; Q, TaqI; S, Sau3AI; R, RsaI; D, DraI. The arrows indicate the DNA segments inserted into the replicative-form DNA of M13mp18 for sequencing.

In this communication, we report the sequence of the entire coding region as well as the putative promoter of eta. We have also determined the $\mathrm{N}$-terminal amino acid sequence of sETA protein.

\section{METHODS}

Bacterial strains and media. S. aureus strain ZM, an ETA-producing strain, and E. coli transformant strain Ceta, carrying the cloned eta gene, were as described previously (Kondo et al., 1973; Sakurai et al., 1987). Phage M13mp18 and E. coli JM109 were included in a sequencing kit obtained from Takara Shuzo (Tokyo).

ET-broth (Sakurai et al., 1987) and L-broth (Miller, 1972) were used for growth of S. aureus and E. coli respectively. ET-agar and L-agar were also prepared by adding $15 \mathrm{~g}$ or, for soft agar, $5 \mathrm{~g}$ purified agar to 1 litre of ET-broth and L-broth, respectively.

DNA sequencing. The recombinant plasmid, pETA-J3, was described previously (Sakurai et al., 1987). A $1.45 \mathrm{~kb}$ DNA fragment containing the eta gene was isolated from pETA-J3 by $A l u I$ and TaqI digestion. This segment was cleaved with restriction endonucleases $A l u I$, TaqI, Sau3AI, RsaI and DraI to give fragments of suitable size for sequencing. These were ligated to the replicative-form DNA of M13mp18 and used to transfect E. coli JM109. The phages isolated from colourless plaques were used to infect JM109. Single-stranded DNA was purified and sequenced by the dideoxy chain termination method (Sanger et al., 1977, 1980; Sanger, 1981; Messing \& Vieira, 1982) using $\left[\alpha^{-32} \mathrm{P}\right] \mathrm{dCTP}$ (ICN Radiochemicals). The DNA sequence was analysed using the DNASIS computer program (Hitachi Software Engineering Co.).

Determination of $N$-terminal amino acid sequence of ETA. The ETA produced by $S$. aureus strain ZM was purified by HPLC on a Hitachi 3013-0 column, and subjected to $\mathrm{N}$-terminal sequence determination by the method of Tarr (1986) with a gas-phase protein sequencer (model 470A, ABI Co.) and on-line PTH amino acid analyser (model 120A PTH Analyzer, ABI Co.).

\section{RESULTS AND DISCUSSION}

Nucleotide sequence of the eta gene. The restriction map of the et $a$ fragment and the sequencing strategy are shown in Fig. 1. The nucleotide sequence of the $1454 \mathrm{bp}$ fragment containing the eta gene was obtained in both strands (Fig. 2). One open reading frame (ORF), extending from residue 374 to residue 1213 , was identified by computer analysis. The TAA codon at position 
AluI

agCTATAAGAGT CAGAAAAACA GCAGGATTAA CCGGCACTGT CGTTGAAGAA GATTCATGGC

TATACACAAA AGATGATTGG GTAAAATTCG ATCAAGTAAT TAAAAAAGAT GGCTACTGGT

GGATTAGATT CAAATATCAA CGTGAGGGCT CTAGTACTAA CGATTTTTTT TGTGCAGTAT

GTAGAATCAC TGACAAGGAA CAAAAGATTA AAAATGAAAA ATATTGGGGA ACTATTGAGT

AGGATGATTA ATA ATG AAT ATT AGT AAA ATT ATT TCT AAA GTT TTA TTG TCT TTA TCT CTA 42l

\begin{tabular}{lllllllllllllllll} 
SD & $M$ & $N$ & $N$ & $S$ & $K$ & $I$ & $I$ & $S$ & $K$ & V & L & L & S & L & S & L \\
\hline I & & & & 5 & & & & & 10 & & & & & 15 &
\end{tabular}

TTT ACT GTA GGA GCT AGT GCA TTT GTT ATT CAA GAC GAA CTG ATG CAA AAA AAC CAT GCA $\begin{array}{lllllllllllllllllllllllllll} & T & T & G & A & S & A & F & V & I & Q & D & E & L & M & E & K & N & H & A\end{array}$ AAA GCA GAA GTT TCA GCA GAA GAA ATA AAA AAA CAT GAA GAG AAA TGG AAT AAG TAC TAT $\begin{array}{lllllllllllllllllllll}\mathrm{K} & \mathrm{A} & \mathrm{E} & \mathrm{V} & \mathrm{S} & \mathrm{A} & \mathrm{E} & \mathrm{E} & \mathrm{I} & \mathrm{K} & \mathrm{K} & \mathrm{H} & \mathrm{E} & \mathrm{E} & \mathrm{K} & \mathrm{W} & \mathrm{N} & \mathrm{K} & \mathrm{Y} & \mathrm{Y}\end{array}$ $38 \mid 39$

GGT GTC AAT GCA TTT AAT TTA CCA AAA GAG CTT TTT AGT AAA GTT GAT GAA AAA GAT AGA $\begin{array}{lllllllllllllllllllll}G & V & N & A & F & N & L & P & K & E & L & F & S & K & V & D & E & K & D & R\end{array}$ CAA AAG TAT CCA TAT AAT ACT ATA GGT AAT GTT TTT GTA AAA GGA CAA ACA AGT GCA ACT $\begin{array}{lllllllllllllllllllll}\mathrm{Q} & \mathrm{K} & \mathrm{Y} & \mathrm{P} & \mathrm{Y} & \mathrm{N} & \mathrm{T} & \mathrm{I} & \mathrm{G} & \mathrm{N} & \mathrm{V} & \mathrm{F} & \mathrm{V} & \mathrm{K} & \mathrm{G} & \mathrm{Q} & \mathrm{T} & \mathrm{S} & \mathrm{A} & \mathrm{T}\end{array}$ GGT GTG TTA ATT GGA AAA AAT ACA GTT CTA ACA AAT AGA CAT ATC GCT AAA TTT GCT AAT $\begin{array}{lllllllllllllllllllll}G & V & L & I & G & K & N & T & V & L & T & N & R & H & I & A & K & F & A & N\end{array}$ GGA GAT CCA TCT AAA GTA TCT TTT AGA CCT TCT ATA AAT ACA GAT GAT AAC GGT AAT ACT $\begin{array}{lllllllllllllllllllll}G & D & P & S & K & V & S & F & R & P & S & I & N & T & D & D & N & G & N & T\end{array}$ GAA ACA CCA TAT GGA GAG TAT GAA GTC AAA GAA ATA TTA CAA GAA CCA TTT GGT GCA GGT $\begin{array}{lllllllllllllllllllll}E & T & P & Y & G & E & Y & E & V & K & E & I & L & Q & E & P & F & G & A & G\end{array}$ GTT GAT TTA GCA TTA ATC AGA TTA AAA CCA GAT CAA AAC GGT GTT TCA TTA GGC GAT AAA $\begin{array}{lllllllllllllllllllll}V & D & L & A & L & I & R & L & K & P & D & Q & N & G & V & S & L & G & D & K\end{array}$ ATA TCC CCA GCA AAA ATA GGG ACA TCT AAT GAT TTA AAA GAT GGA GAC AAA CTC GAA TTA $\begin{array}{lllllllllllllllllllll}I & S & P & A & K & I & G & T & S & N & D & L & K & D & G & D & K & L & E & L\end{array}$ ATA GGC TAT CCA TTC GAT CAT AAA GTT AAC CAA ATG CAC AGA AGT GAA ATT GAG TTA ACA $\begin{array}{lllllllllllllllllllll}I & G & Y & P & F & D & H & K & V & N & Q & M & H & R & S & D & I & D & L & T\end{array}$ ACT TTA TCA AGA GGA TTA AGA TAC TAT GGA TTT ACA GTT CCG GGA AAT TCT GGA TCA GGT

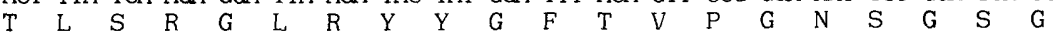
ATA TTT AAT TCA AAT GGA GAA TTA GTT GGT ATA CAT TCT AGG AAA GTG TCT CAT ATT GAT $\begin{array}{llllllllllllllllllll}I & F & N & S & N & G & E & L & V & G & I & H & S & S & K & V & S & H & L & D\end{array}$ AGA GAG CAT CAA ATA AAT TAT GGT GTT GGT ATT GGG AAT TAT GTC AAG CGC ATT ATA AAC 1201 $\begin{array}{lllllllllllllllllllll}R & E & H & Q & I & N & Y & G & V & G & I & G & N & Y & V & K & R & I & I & N\end{array}$ GAG AAA AAT GAG TAA TAAA TAAAATAAAA ATCCGTGGAT GTTTATACA AAACTTATAT 1260 $\mathrm{E} \quad \mathrm{K} N \mathrm{E} 280$

TITATAGCAG TAAGAAGCTG ACTGCATATT TAAACCACCC ATACTAGTTA CTGGGTGGTT 1320 GTTTTTTTAT GTTATATTAT AAATGATCAA ACTACACCAC CTATTAATTT AGGAGTGTGG 1380 mRNA stop TTATTTTAAT ATGCGAAGCT AAAATAACTA CAAATGATAC CATTTTTGAT ACCAAAAAAT 1440 AATAACCTCA AATT $\frac{\text { cga }}{\text { Togl }}$ 1454

Fig. 2. Nucleotide sequence of the $A l u I-T a q I$ fragment containing the eta gene. The amino acids of the polypeptide deduced from the nucleotide sequence are shown with single-letter symbols under the triplet codons. Nucleotide sequence numbers are shown on the right; amino acid sequence numbers are shown below the appropriate amino acid. Three sets of -35 and -10 regions corresponding to the consensus sequence of the $E$. coli promoter are indicated with solid lines above the respective sequences. $\mathrm{SD}$, ribosome-binding region (Shine-Dalgarno sequence). Four inverted sequences are underlined with arrows indicating the direction of the inversion. The stop codon for the translation of mRNA (TAA) and the termination codon for mRNA transcription are indicated by asterisks and dotted underlining respectively.

1214 is considered to be the translation termination codon. This 840 bp sequence codes for a polypeptide of 280 amino acid residues (Fig. 2). Two promoter-like sequences were recognized in sequences $5^{\prime}$ to this ORF stretch, at nucleotides 235-273 and 295-333. Several plausible -35 and -10 regions corresponding to the consensus sequence of the $E$. coli promoter (Hawley \& McClure, 1983) were apparent, each separated by 16-18 bp (Fig. 2). A potential ribosomebinding site (Shine-Dalgarno sequence), AGGATG, was identified starting at position 361 with optimal spacing ( $7 \mathrm{bp}$ ) from the initiation codon ATG. 
Table 1. N-terminal amino acid sequence of ETA from S. aureus strain ZM

The sequence shown was determined chemically. It is identical to that deduced from the eta nucleotide sequence, the N-terminal Glu residue corresponding to the 39th amino acid in the sequence shown in Fig. 2.

$\begin{aligned} \begin{array}{r}\text { Residue } \\ \text { no. }\end{array} & \begin{array}{c}\text { Amino } \\ \text { acid }\end{array} \\ 1 & \text { Glu } \\ 2 & \text { Val } \\ 3 & \text { Ser }(\mathrm{Thr})^{*} \\ 4 & \text { Ala } \\ 5 & \text { Glu } \\ 6 & \text { Glu } \\ 7 & \text { Ile } \\ 8 & \text { Lys } \\ 9 & \text { Lys } \\ 10 & \text { His } \\ 11 & \text { Glu } \\ 12 & \text { Glu }\end{aligned}$

\begin{tabular}{cl}
$\begin{array}{c}\text { Residue } \\
\text { no. }\end{array}$ & \multicolumn{1}{c}{$\begin{array}{c}\text { Amino } \\
\text { acid }\end{array}$} \\
13 & Lys \\
14 & Trp \\
15 & Asn (Asp)* \\
16 & Lys \\
17 & Tyr \\
18 & Tyr \\
19 & Gly \\
20 & Val \\
21 & Asn (unknown)* \\
22 & Ala (Asx)* \\
23 & Phe \\
24 & Asn
\end{tabular}

$\begin{array}{cc}\begin{array}{c}\text { Residue } \\ \text { no. }\end{array} & \begin{array}{c}\text { Amino } \\ \text { acid }\end{array} \\ 25 & \text { Leu } \\ 26 & \text { Pro } \\ 27 & \text { Lys } \\ 28 & \text { Glu } \\ 29 & \text { Leu } \\ 30 & \text { Phe } \\ 31 & \text { Ser } \\ 32 & \text { Lys } \\ 33 & \text { Val } \\ 34 & \text { Asp } \\ 35 & \text { Glu }\end{array}$

* Johnson et al. (1979) sequenced the N-terminus of ETA from S. aureus strain TA, as far as residue 23. That sequence was identical to the one shown except for the amino acids in parentheses.

$N$-terminal amino acid sequence and putative signal peptide. The 35 amino acid residues constituting the N-terminal sequence of mature ETA purified from $S$. aureus ZM culture supernate were determined (Table 1). The first amino acid, glutamic acid (E), corresponds to the 39 th residue in the amino acid sequence deduced from the nucleotide sequence of the cloned eta gene; the following 34 residues were identical to those deduced from the DNA sequence. Since the 39th amino acid was identified as the $\mathrm{N}$-terminal residue of the mature toxin, the signal sequence is presumed to consist of the preceding 38 amino acid residues (Fig. 2).

The hydropathy profile of the eta gene product (Fig. 3) shows that the N-terminal sequence contains a markedly hydrophobic stretch in the middle. Although this putative signal peptide is long, it is still within the range for a signal peptide of a protein excreted from Gram-positive bacteria. For example, protein A contains a signal sequence of 36 amino acid residues (Uhlen $e t$ al., 1983) whereas ETB has 31 (Jackson \& Iandolo, 1986).

Molecular mass and amino acid composition of ETA predicted from the DNA sequence. The amino acid composition of ETA predicted from the eta gene structure is in close agreement with that of ETA derived from S. aureus strain TA reported by Johnson et al. (1979), with only minor differences: the predicted eta gene product contains four more Val residues, two more Leu residues and one more Gly residue, but two fewer Glu + Gln residues. The total number of amino acid residues of the predicted eta gene product is 242 , five more than reported by Johnson et al. (1979). The molecular mass of ETA calculated from these 242 amino acids $(26.9 \mathrm{kDa})$ is somewhat larger than that $(24 \mathrm{kDa})$ estimated by gel filtration in our previous experiments (Kondo et al., 1973).

Potential secondary structure in the $5^{\prime}$ and $3^{\prime}$ flanking regions of the eta gene. The $5^{\prime}$ flanking regions contain two inverted repeats (Figs 2 and 4). Both partially overlap the -10 region of the putative promoters and thus may play regulatory roles. Inverted repeats were also identified at two positions in the $3^{\prime}$ flanking region: the one farthest from the ORF was GC rich and was followed by seven $\mathrm{T}$ residues; it may correspond to a $\rho$-dependent transcription terminator (Rosenberg \& Court, 1979).

In conclusion, several characteristic structures of the eta gene and its product were identified: double promotor regions, two inverted sequences in both the $5^{\prime}$ and the $3^{\prime}$ flanking regions, a long signal sequence consisting of 38 amino acid residues, and an $\mathrm{N}$-terminal segment 


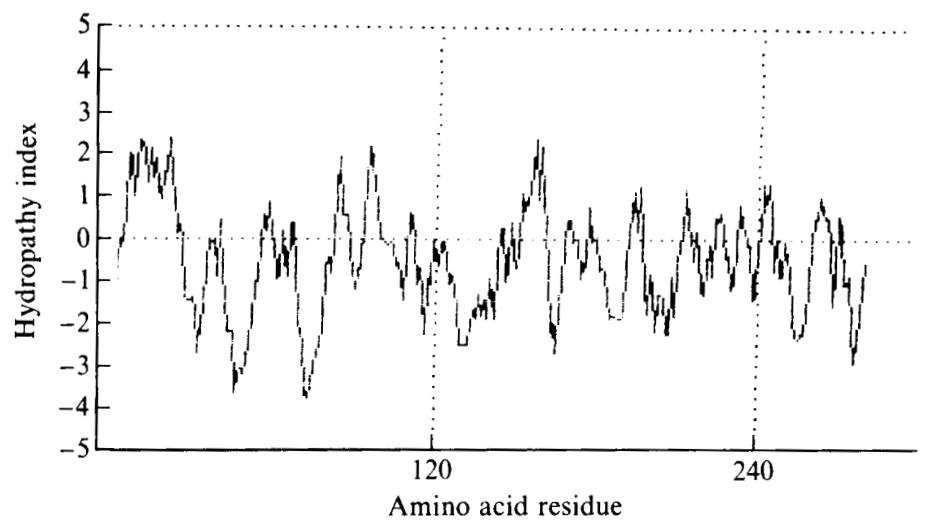

Fig. 3. Hydropathy profile of the eta gene product. The vertical axis indicates the relative hydrophobicity (negative values) or relative hydrophilicity (positive values). The horizontal axis denotes the amino acid residues, numbered from the first amino acid of the primary eta gene product. Each interval between two dots in the dotted horizontal lines corresponds to four amino acid residues. Hydrophobicity of the derived cETA protein was determined according to Kyte \& Doolittle (1982) using a window of four amino acid residues.

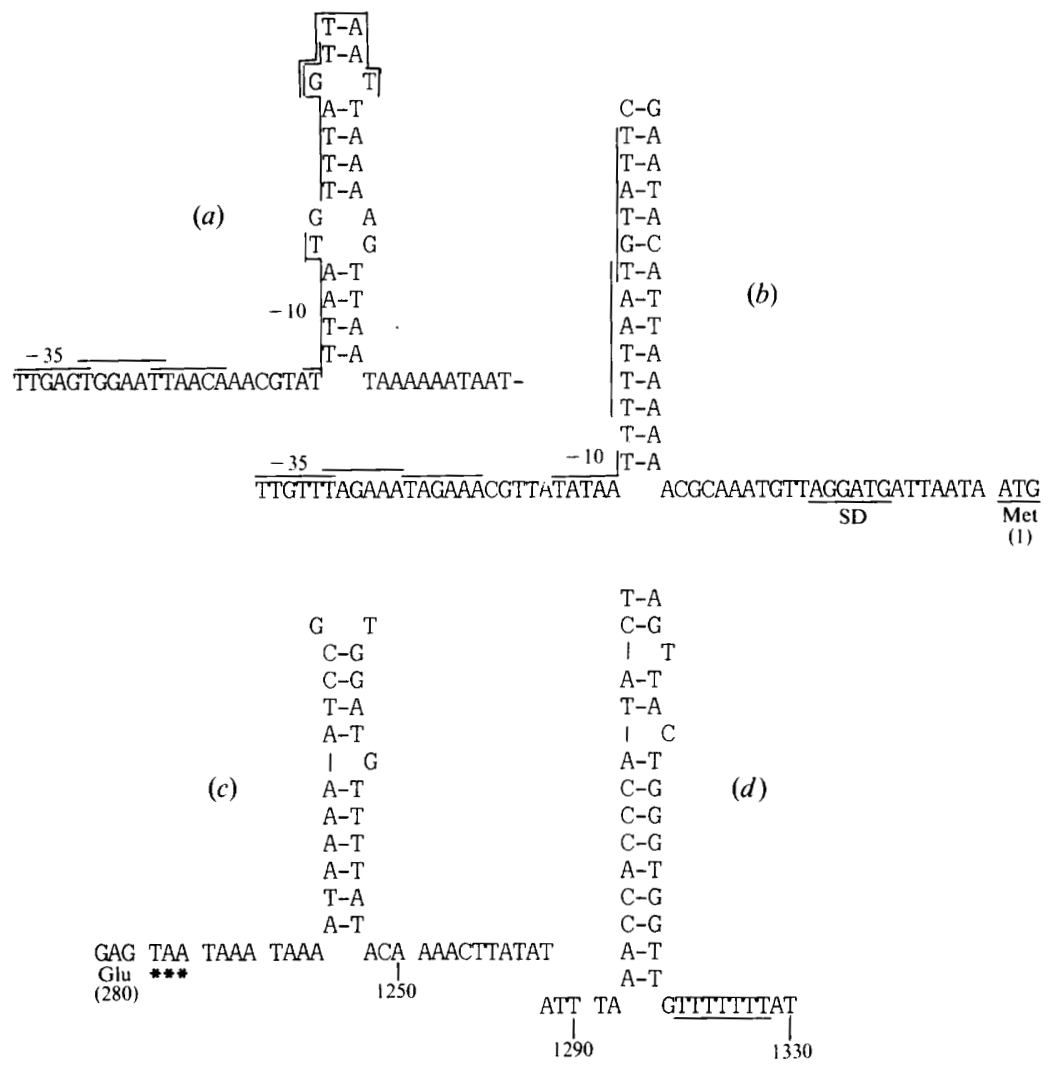

Fig. 4. Inverted sequences in the $5^{\prime}$ and $3^{\prime}$ flanking regions of the ETA coding sequence. $(a, b)$ Inverted sequences upstream of the presumed SD sequence. Promoter-like sequences ( -35 and -10 regions) are indicated by lines above the respective hexanucleotides. Note that both -10 regions overlap the inverted sequences. $(c, d)$ Inverted sequences in the $3^{\prime}$ flanking region of the eta gene. The numbers in parentheses are amino acid sequence numbers. The stop codon is marked with asterisks. Nucleotide sequence numbers (see Fig. 2) are also shown. 
containing a markedly hydrophobic region in the middle. However, it is not yet known what domains in the nucleotide sequence of this gene play essential roles in coding for the biological properties of ETA.

We have recently cloned the gene coding for ETB $(e t b)$ and determined the DNA sequence (unpublished results). It was different from the $e t b$ sequence reported by Jackson \& Iandolo (1986), but Lee $e t$ al. (1987) have presented a revised DNA sequence of $e t b$ in addition to the sequence of the eta gene, and our data on eta are in agreement with their eta sequence except for minor differences in $5^{\prime}$ and $3^{\prime}$ flanking regions. The DNA sequence of $e t b$ which we recently obtained is also in agreement with their revised $e t b$ sequence. The comparative analyses between the $e t a$ and $e t b$ genes cloned in our department are now being carried out.

This work was partially supported by a grant-in-aid for special project no. 60108603 from the Ministry of Education, Science and Culture, Japan. We thank Professor N. Yamamoto, Department of Microbiology and Immunology, Hahneman University School of Medicine, for his kind discussion of this work and also thank Miss R. Nakayama for technical assistance.

\section{REFERENCES}

Arbuthnott, J. P., Kent, J., Lyell, A. \& Gemmell, C. G. (1971). Toxic epidermal necrolysis produced by an extracellular product of Staphylococcus aureus. British Journal of Dermatology 85, 145-149.

Hawley, D. K. \& McClure, W. R. (1983). Compilation and analysis of Escherichia coli promoter DNA sequences. Nucleic Acids Research 11, 2237-2255.

JACKSON, M. P. \& IANDOLO, J. J. (1986). Sequence of the exfoliative toxin B gene of Staphylococcus aureus. Journal of Bacteriology 166, 574-580.

Johnson, A. D., Spero, L., CADES, J. S. \& De Cicco, B. T. (1979). Purification and characterization of different types of exfoliative toxin from Staphylococcus aureus. Infection and Immunity 24, 679-684.

Kapral, F. A. \& Miller, M. M. (1971). Product of Staphylococcus aureus responsible for the scalded skin syndrome. Infection and Immunity 4, 541-545.

Kondo, I. \& SakuRaI, S. (1980). Studies on toxicity and immunology of staphylococcal exfoliatin $A$ and B. In Natural Toxins, pp. 379-387. Edited by D. Eaker \& T. Wadström. Oxford \& New York: Pergamon Press.

Kondo, I., Sakurai, S. \& Sarai, Y. (1973). Purification of exfoliatin produced by Staphylococcus aureus of bacteriophage group 2 and its physicochemical properties. Infection and Immunity 8, 156-164.

KondO, I., SakuraI, S. \& Saral, Y. (1974). New type of exfoliatin obtained from staphylococcal strains, belonging to phage groups other than group 2, isolated from patients with impetigo and Ritter's disease. Infection and Immunity 10, 851-861.

Kondo, I., Sakurai, S., Sarai, Y. \& Futaki, S. (1975). Two types of exfoliatin and their distribution in staphylococcal strains isolated from patients with scalded skin syndrome. Journal of Clinical Microbiology 1, 397-400.

Kyte, J. \& Doolittle, F. R. (1971). Product of Staphylococcus aureus responsible for the scalded skin syndrome. Infection and Immunity 4, 541-545.

LEE, C. Y., SCHMIDT, J. J., JoHNSON-WingeR, A. D., SPERO, L. \& IANDOLO, J. J. (1987). Sequence determination and comparison of the exfoliative toxin A and toxin B cloned from Staphylococcus aureus. Journal of Bacteriology 169, 3904-3909.

Melish, M. F. \& Glasgow, L. A. (1970). The staphylococcal scalded skin syndrome: development of an experimental model. New England Journal of Medicine 282, 1114-1119.

Messing, J. \& VieIRA, J. (1982). A new pair of M13 vectors for selecting either DNA strand of doubledigest restriction fragments. Gene 19, 269-276.

MILLER, J. H. (editor) (1972). Experiments in Molecular Genetics. Cold Spring Harbor, NY: Cold Spring Harbor Laboratory.

O'TOOLE, L. L. \& FosTER, T. J. (1986a). Epidermolytic toxin serotype B of Staphylococcus aureus is plasmidencoded. FEMS Microbiology Letters 36, 311-314.

O'TOOLE, L. L. \& Foster, T. J. (1986b). Molecular cloning and expression of epidermolytic toxin A gene of Staphylococcus aureus. Microbial Pathogenesis 1, 583-594.

Rogolsky, M., Warken, R., Wiley, B. B., NakaMURA, H. T. \& GlasGow, L. A. (1974). Nature of the genetic determinant controlling exfoliative toxin production in Staphylococcus aureus. Journal of Bacteriology 117, 157-165.

Rogolsky, M., Wiley, B. B. \& Glasgow, L. A. (1976). Phage group 2 staphylococcal strains with chromosomal and extrachromosomal genes for exfoliative toxin production. Infection and Immunity 13, 44-52.

RosenberG, M. \& Court, D. (1979). Regulatory sequences involved in the promotion and termination of RNA transcription. Annual Review of Genetics 13, 319-353.

Sakurai, S., Suzuki, H. \& Kondo, I. (1987). Cloning of the gene coding for staphylococcal exfoliative toxin A and its expression in Escherichia coli. FEMS Microbiology Letters 42, 63-67.

SANGER, F. (1981). Determination of nucleotide sequences in DNA. Science 214, 1205-1210.

Sanger, F., Nicklen, S. \& Coulson, A. R. (1977). DNA sequencing with chain-terminating inhibitors. Proceedings of the National Academy of Sciences of the United States of America 74, 5463-5467.

Sanger, F., Coulson, A. R., Barvell, B. G., SMith, A. J. H. \& ROE, B. A. (1980). Cloning in singlestranded bacteriophage as an aid to rapid DNA sequencing. Determination of nucleotide sequences in DNA. Science 214, 1205-1210. 
TARR, G. E. (1986). A practical manual. In Microcharacterization of Polypeptides, pp. 155-194. Edited by J. E. Shively. Clifton, NJ: Humana Press.

Uhlen, M., Guss, B., Nilsson, B., Gatenbeck, S., Philipson, L. \& Lindberg, M. (1983). Complete sequence of the staphylococcal gene encoding pro- tein A - a gene evolved through multiple duplications. Journal of Biological Chemistry 259, 1695-1702.

WILEY, B. B. \& ROGOLSKY, M. (1977). Molecular and serological differentiation of staphylococcal exfoliative toxin synthesized under chromosomal and plasmid control. Infection and Immunity 18, 487-494. 